\title{
CRENÇAS DETERMINANTES DA INTENÇÃO DA ENFERMEIRA ACERCA DA PRESENÇA DOS PAIS EM UNIDADES NEONATAIS DE ALTO-RISCO
}

Lisabelle Mariano Rossato-Abéde ${ }^{1}$ Margareth Angelo ${ }^{2}$

Rossato-Abéde LM, Angelo M. Crenças determinantes da intenção da enfermeira acerca da presença dos pais em unidades neonatais de altorisco. Rev Latino-am Enfermagem 2002 janeiro-fevereiro; 10(1):48-54.

O presente estudo tem como objetivo conhecer as crenças, as atitudes e as normas sociais determinantes da intenção da enfermeira em possibilitar a presença dos pais em unidades neonatais de alto-risco. 0 conteúdo de entrevistas semi-estruturadas com 11 enfermeiras foi analisado tendo como referencial teórico a Teoria da Ação Racionalizada. Os núcleos temáticos permitiram compreender a relação existente entre a intenção e o comportamento da enfermeira em permitir a presença dos pais na UTI Neonatal e a influência das crenças pessoais e das normas subjetivas no comportamento da enfermeira.

DESCRITORES: atitude, família, recém-nascido

\section{BELIEFS DETERMINING THE NURSE'S INTENTION CONCERNING THE PRESENCE OF PARENTS IN NEONATAL INTENSIVE CARE UNITS}

This study aims at learning about the beliefs, attitudes and social rules which determine the nurse's intention to allow the presence of parents in Neonatal Intensive Care Units. The content of semi-structured interviews conducted with 11 nurses was analyzed by using the Rationalized Action Theory as a theoretical framework. The thematic units enabled the comprehension of the relationship between the nurse's intention and behavior when allowing the presence of parents in Neonatal Intensive Care Units as well as the influence of the nurse's personal beliefs and subjective norms on her behavior.

KEY WORDS: Attitude, family, newborn

\section{CREENCIAS DETERMINANTES DE LA INTENCIÓN DE LA ENFERMERA ACERCA DE LA PRESENCIA DE LOS PADRES EN LOS CENTROS NEONATALES DE ALTO RIESGO}

El presente estudio tiene como objetivo conocer las creencias, actitudes y normas sociales que determinan la intencionalidad de la enfermera para posibilitar que los padres estén presentes en las unidades neonatales de alto riesgo. El contenido de entrevistas, semiestructuradas, realizadas con 11 enfermeras fue analizado teniendo como referencial teórico la Teoría de la Acción Racionalizada. Los núcleos temáticos permitieron comprender la relación existente entre la intención y el comportamiento de la enfermera para permitir la presencia de los padres en la UCI Neonatal y la influencia de las creencias personales y de las normas subjetivas en el comportamiento de la enfermera.

DESCRIPTORES: actitud, familia, recién nacido

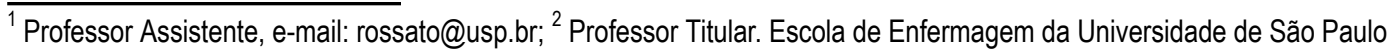




\section{INTRODUÇÃO}

Assistir à família da criança hospitalizada é um dos atributos da enfermeira desde o advento do Programa Mãe Participante ${ }^{(1)}$.

Características peculiares deste papel incluem a habilidade de reconhecer e conviver com a família na situação de doença, incluindo-a no planejamento do cuidado da criança bem como respeitando suas decisões em relação ao tratamento. Além disso, acreditamos que ao valorizar a presença da família durante 0 tratamento da criança, a enfermeira desempenha um papel singular no cuidado aos pais, em particular no contexto da UTI Neonatal.

0 conhecimento existente na área de enfermagem da família ainda é incipiente no Brasil ${ }^{(2)}$, entretanto, podemos notar um número crescente de pesquisas sobre famílias, em nosso meio, que vem determinando transformações na maneira como ela é percebida na situação hospitalar.

Pesquisas realizadas neste contexto têm destacado dois aspectos relevantes sobre o tema: a necessidade manifestada pelos pais de recém-nascidos e por enfermeiras sobre a importância de incentivar a interação pais-criança ${ }^{(3-7)}$ e a existência de barreiras a esta interação em UTIs Neonatais ${ }^{(8-9)}$.

Paralelamente, observamos que, na prática clínica, o desempenho do papel da enfermeira junto aos pais nem sempre revela ações de apoio à interação pais-recém-nascido.

Refletindo sobre estas evidências, direcionamos nossa atenção para a compreensão dos elementos que poderiam estar contribuindo para esta situação, formulando o questionamento: o que determina o comportamento da enfermeira em relação aos pais em UTIs Neonatais?

Buscando respostas para esta indagação, encontramos na Teoria da Ação Racionalizada ${ }^{(10)}$, um caminho para entender as intenções da enfermeira em se engajar no comportamento de permitir a presença dos pais na unidade neonatal. Esta teoria, descrita em 1975 por Azhen; Fishbein lida com as relações existentes entre crenças, atitudes, intenções e comportamentos e baseia-se no pressuposto de que as pessoas são seres racionais e que 0 comportamento está sob controle volitivo. Isto não significa que 0 comportamento seja sempre racionalizado, mas que ele resulta logicamente de qualquer informação que a pessoa tenha disponível.

De acordo com esta teoria, o que melhor prediz 0 comportamento é a intenção em desempenhá-lo. A intenção é determinada pelas atitudes do indivíduo em relação a desempenhar o comportamento (fatores pessoais) e as expectativas normativas sociais percebidas pelo indivíduo quanto ao desempenho do comportamento (fator social). Tanto atitudes como normas sociais são formulações de expectativas e valor. Para os autores, a atitude é a soma dos resultados de crenças específicas sobre as conseqüências de manifestar o comportamento (expectativa) e a avaliação correspondente (bom ou mau) daquele resultado (valor). Norma social é a soma dos resultados de crenças normativas específicas que 0 indivíduo traz sobre expectativas de pessoas significativas, em relação ao comportamento (expectativa) e a motivação do indivíduo para aceder a estas expectativas (valor) ${ }^{(10)}$.

As relações entre as variáveis da teoria podem ser visualizadas na Figura 1.

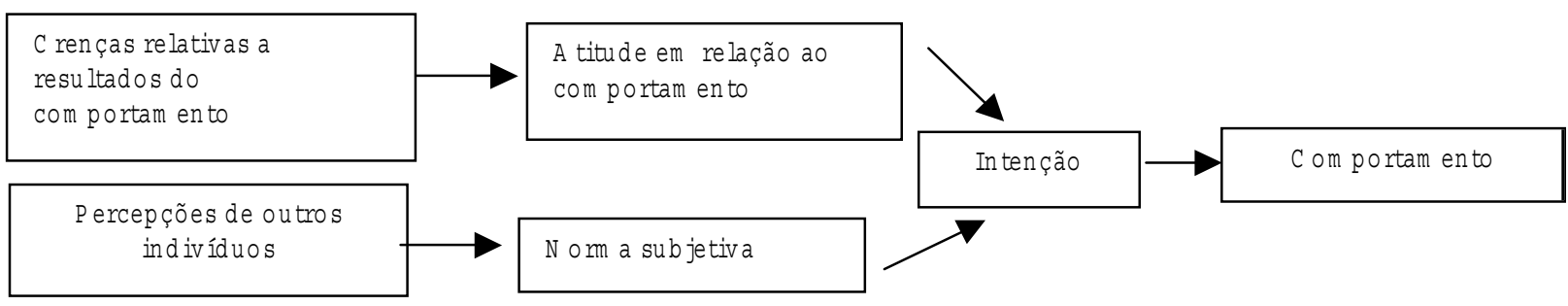

Figura 1 - Relação entre crenças, atitude, normas subjetivas, intenção e comportamento na T.A.R. ${ }^{(10)}$

A Figura 1 descreve a relação entre a estimativa de uma atitude, baseada em crenças comportamentais e a avaliação de resultados. Da mesma maneira, apresenta a correlação entre norma subjetiva, baseada em crenças normativas e motivação para desempenhar o comportamento. Segundo a Teoria da Ação Racionalizada ${ }^{(10)}$, as atitudes e as normas subjetivas são as variáveis utilizadas para predizerem a intenção. Ainda na Figura 1 observa-se a relação direta existente entre a intenção e a ocorrência do comportamento.

Assim, de acordo com a Teoria da Ação Racionalizada, os indivíduos têm maior probabilidade de desempenhar comportamentos se tais ações são vistas como instrumental para alcançar conseqüências desejáveis e são consideradas compensadores por pessoas ou grupos que o indivíduo deseja agradar.

As normas subjetivas da intenção da enfermeira foram estudadas utilizando o mesmo referencial confirmando o potencial desta Teoria para a melhor compreensão de atitudes e crenças subjacentes aos comportamentos observados. Destacamos dois estudos, um sobre o comportamento de documentação da enfermeira ${ }^{(11)}$ e outro acerca do comportamento de avaliação da dor 
pela enfermeira ${ }^{(12)}$, onde ambos ressaltam a contribuição das normas subjetivas para a intenção do comportamento das enfermeiras.

Tendo como base o referencial teórico da Teoria da Ação Racionalizada, estabelecemos para este estudo o seguinte objetivo: - descrever as crenças, as atitudes e as normas sociais determinantes da intenção da enfermeira em possibilitar a presença de pais em unidades neonatais de alto-risco.

\section{CAMINHO METODOLÓGICO}

O estudo foi realizado em duas unidades de terapia intensiva neonatais de um hospital de ensino da cidade de São Paulo. As participantes deste estudo foram 11 enfermeiras, com idade entre 24 e 36 anos, tempo de formada de 1 mês a 16 anos e experiência na instituição de 1 mês a 14 anos.

Os dados foram coletados por meio de entrevistas semiestruturadas, cujas perguntas foram orientadas pela Teoria da Ação Racionalizada. 1) $O$ que você pensa sobre a presença dos pais em unidade neonatal de alto-risco?, 2) Quais são os benefícios dessa presença?, 3) Quais são os malefícios dessa presença?, 4) O que a equipe pensa sobre a presença dos pais na unidade neonatal de alto-risco?, 5) 0 que a instituição estabelece quanto aos pais em unidade neonatal de alto-risco?, 6) O que os pais pensam sobre estar presente na unidade neonatal de alto-risco?, 7) Geralmente, como você age em relação à presença dos pais na unidade neonatal de alto-risco?

As entrevistas foram realizadas no próprio hospital, onde a pesquisadora contatou, pessoalmente, as participantes, esclarecendo-as sobre o objetivo e a metodologia do estudo. Após fazer esses esclarecimentos, foi obtido o consentimento verbal das enfermeiras para a entrevista, assegurando-lhes a liberdade de recusar ou desistir de participar em qualquer fase do estudo, sem qualquer prejuízo. Do mesmo modo, foram garantidos o sigilo absoluto das informações e o anonimato quanto à identificação das enfermeiras.

\section{ANÁLISE DOS DADOS}

A análise dos dados foi realizada em duas etapas. $\mathrm{Na} \mathbf{1}^{\mathrm{a}}$ etapa, em função da natureza dos dados obtidos, utilizou-se o método de Análise de Conteúdo ${ }^{(13)}$ buscando identificar núcleos temáticos presentes nas respostas das enfermeiras.

Os passos seguidos nesta etapa de análise de conteúdo foram: 1. Todas as informações relacionadas ao tema estudado foram extraídas das respostas, de modo a possibilitar a organização dos dados e a obtenção de códigos. 2. Todas as informações relativas a cada código foram reunidas, para que se pudesse proceder a uma classificação do conteúdo segundo características comuns, dando origem a categorias de análise. 3. A partir das categorias procedeuse a análise propriamente dita, que consistiu em interpretar as categorias, objetivando extrair o significado contido nas mesmas e a identificação de núcleos temáticos característicos da experiência das enfermeiras.

$\mathrm{Na} 2^{\mathrm{a}}$ etapa, uma vez identificados os núcleos temáticos, a eles foram aplicados os princípios da Teoria da Ação Racionalizada ${ }^{(10)}$. Esta análise consistiu no estabelecimento de relações existentes entre os núcleos temáticos e na identificação das atitudes e normas sociais determinantes das intenções e comportamentos das enfermeiras em relação à presença dos pais na UTI Neonatal.

\section{RESULTADOS}

Núcleos temáticos

A análise das respostas das enfermeiras possibilitou a identificação de 6 núcleos temáticos relativos à questão da presença dos pais em UTI. A seguir serão apresentadas as descrições dos núcleos temáticos, que caracterizam as percepções das enfermeiras estudadas:

A presença dos pais atende a necessidade de contato entre pais, recém-nascidos e equipe

Segundo as enfermeiras, a presença, sobretudo da mãe, possibilita que a criança receba sua atenção e seja amamentada.

Melhora muito o restabelecimento da criança, quando a mãe visita.

A mãe tranqüiliza a criança, afastando inclusive a experiência de abandono por parte da mãe.

A criança sente que não foi abandonada.

Durante a permanência da criança na unidade, que pode ser longa, os pais vão começando a se sentir mais aptos e mais à vontade para oferecer auxílio no cuidado ao filho e também para fazer perguntas.

Os pais vão aprendendo a cuidar da criança.

A possibilidade de maior contato com o filho na UTI Neonatal resulta ainda em maior esclarecimento das dúvidas dos pais a respeito da doença da criança.

Querem saber quando a criança vai embora, saber da sua doença.

De acordo com as enfermeiras, um maior contato físico e afetivo entre pais e recém-nascido é fundamental para fortalecer 0 
vínculo em formação.

Às vezes não gostam da criança a princípio.

As enfermeiras percebem também que conforme os pais freqüentam mais a unidade, começam a confiar na equipe que presta assistência à criança; o que resulta numa diminuição da ansiedade que 0 ambiente lhes transmite.

Ficam mais à vontade conforme o que vão aprendendo fazer.

A presença dos pais prejudica o andamento do serviço na unidade

A presença dos pais na unidade neonatal de alto risco implica no desenvolvimento de certas ações pela equipe que interferem no andamento do serviço.

Os pais querem saber tudo.

As informações visam também esclarecer aquilo que os pais estão vendo e não compreendem, por não terem vivência de UTI Neonatal.

Não entendem os procedimentos, acham que estão maltratando a criança.

A presença dos pais interfere também no andamento dos cuidados, já que em virtude da proximidade com 0 filho, alguns procedimentos precisam ser realizados novamente ou 0 atendimento da criança deve ser atrasado.

As mães perdem as veias.

Neste sentido, o prejuízo atribuído à presença dos pais na unidade, relaciona-se ao tempo que deve ser ocupado com eles, além de cuidar do recém-nascido.

Dá mais trabalho para a gente.

Alguns pais atrapalham, outros colaboram

Segundo as enfermeiras, em geral, os pais atrapalham ao se manifestar contrariamente à situação que vivenciam, sobretudo em relação à rotina do serviço e ao atendimento à criança. Ou seja, aqueles pais que não aceitam a rotina do serviço.

Quer ficar além do horário permitido ou cobram algum aspecto da assistência.

Os pais colaboram, quando não criam um clima de confronto entre o que desejam e o que vivenciam.

Quando os pais ajudam, há um bom relacionamento.

A instituição não permite que os pais fiquem o dia todo

Ambas as unidades de terapia intensiva neonatal estabelecem como sendo entre uma e duas horas a duração da visita dos pais ao recém-nascido. Além de limitar o tempo, restringem também o número de pessoas presentes, ou seja, numa unidade apenas uma pessoa por dia visita a criança enquanto que na outra, duas pessoas o fazem.

A única exceção estabelecida pelas unidades relaciona-se à entrada periódica da mãe em função dos horários de amamentação.

A permanência durante todo o dia não é favorecida pelo pouco espaço físico e falta de acomodações como banheiros, salas para descanso.

A enfermeira pode alterar a rotina da presença dos pais na unidade

Embora as enfermeiras trabalhem em instituições que normatizam as visitas dos pais ao recém-nascido, estas possibilidades de contato podem ser alteradas por elas em determinadas circunstâncias. Tais situações relacionam-se, sobretudo à gravidade do estado da criança, à necessidade de amamentação e ao isolamento do recém-nascido.

Se for criança grave não existe rotina rígida.

A mãe pode permanecer à noite inclusive, quando a internação da criança é longa ou esta se encontra em isolamento.

Crianças em isolamento a mãe pode dormir.

A amamentação do filho, segundo o estado da criança, tem seu horário liberado e as mães podem permanecer o dia todo no hospital.

Mães que amamentam permanecem o dia no hospital.

Alterar ou não a rotina de visitas dos pais à unidade neonatal, não depende, segundo a vivência das enfermeiras, apenas da situação em que se encontra a criança. Nestes casos, as enfermeiras também avaliam a família. Assim, os pais devem também apresentar certas condições favoráveis a sua presença na unidade, como: capacidade de compreensão, obedecer às regras da instituição e se preocupar exclusivamente com sua criança.

Não devem ficar conversando com outros pais ou querendo saber das outras crianças.

A enfermeira orienta e ensina os pais

As enfermeiras orientam os pais sobre a organização do serviço de enfermagem, como devem comportar-se na unidade, sobre o funcionamento de aparelhos, como interagir com a criança e sobre a alta.

Oriento os pais sobre a rotina da unidade.

As explicações relacionam-se aos procedimentos que estão sendo realizados na criança e à demonstração da técnica de lavagem das mãos e do uso do avental pelos pais.

Conforme vou fazendo os procedimentos na criança vou explicando aos pais.

Embora não tão freqüentemente como as ações anteriores, algumas enfermeiras procuram oferecer apoio emocional e 
estabelecer maior contato com os pais, visando diminuir a ansiedade deles e estimular sua presença junto ao filho.

Converso no corredor para aliviar a tensão.

Análise segundo a Teoria da Ação Racionalizada (TAR)

Retomando o referencial teórico do estudo, a Teoria da Ação Racionalizada, o que melhor prediz um comportamento é a intenção em desempenhá-Io ${ }^{(10)}$.

Analisando os núcleos temáticos identificados neste estudo, à luz da Teoria da Ação Racionalizada, entendemos que os mesmos possuem certas atribuições típicas das variáveis da teoria e que, portanto, podem ser lidos como tais para explicar a relação existente entre intenção e comportamento da enfermeira em permitir a presença dos pais na UTI Neonatal.

Assim sendo, entendemos que:

1. As crenças da enfermeira quanto à intenção de permitir a presença dos pais na UTI Neonatal são relacionadas a que esta presença atende a necessidade de contato entre pais, RN e equipe, mas também prejudica 0 andamento do serviço na unidade. Desse modo, nota-se que a enfermeira acredita ser esta situação uma conseqüência benéfica para a criança e para os pais e prejudicial ao serviço. Esse seria, segundo a Teoria da Ação Racionalizada, o fator pessoal ou a atitude individual da enfermeira em relação a permitir a presença dos pais na UTI neonatal.

2. As crenças normativas e motivação para desempenhar o comportamento estão evidenciadas quando a enfermeira enfatiza a percepção de elementos da equipe quanto a alguns pais atrapalharem e outros não e também ao fato da instituição não permitir que os pais fiquem o tempo todo. Essas seriam as normas subjetivas ou o fator social identificado pela enfermeira.

3. A intenção da enfermeira, em função da somatória dos fatores pessoais e sociais, é de garantir o cumprimento das normas da instituição para que o serviço não seja prejudicado (fator social) e eventualmente alterar a rotina de acordo com situações identificadas por ela como especiais (fator pessoal).

4. 0 comportamento resultante seria 0 de permitir a presença dos pais conforme a rotina prescrita pela instituição. Essa rotina pode ser alterada segundo a avaliação que a enfermeira faz, tanto sob as condições da criança quanto do comportamento dos pais. 0 comportamento desenvolvido pela enfermeira está diretamente relacionado a sua intenção, ou seja, garantir o cumprimento das normas da instituição para a presença dos pais na UTI Neonatal.

A análise dos temas identificados no estudo segundo a Teoria da Ação Racionalizada pode ser explicitada na Figura 2.



Figura 2 - Relação entre atitudes, normas subjetivas, intenção e comportamento de enfermeiras quanto à presença dos pais em UTI Neonatal

\section{CONSIDERAÇÕES FINAIS}

Os resultados obtidos neste estudo reforçam o conhecimento existente sobre a presença dos pais em UTI Neonatal e as crenças da enfermeira sobre os benefícios da visita para os pais e para o RN

Ao identificar as crenças como sendo as lentes pelas das quais vemos o mundo, é nos revelado que cada pessoa tem sua própria crença baseada na sua história genética e na história de interações com os outros no mundo e que as crenças podem ser boas ou más para a saúde de alguém, podem facilitar, aumentando a possibilidade de solução do problema ou desencorajar a atitude da pessoa, dificultando a solução do problema ${ }^{(14)}$. Percebemos, então, o quanto as crenças do profissional podem ajudar ou prejudicar a presença dos pais na UTI Neonatal.

Dessa maneira, o aparecimento das crenças que norteiam o cuidar da enfermeira, nos resultados deste estudo, veio a constituir um caminho para possibilitar o encontro das respostas para explicar o significado que a enfermeira atribui à presença da família na UTI Neonatal.

Nesse sentido, faz-se necessário entender as crenças da enfermeira para podermos, num segundo momento, compreendermos suas atitudes e sentimentos em relação à experiência da família da criança. 
Em um trabalho considerado clássico sobre a ansiedade de enfermeiras, constatou-se que, do ponto de vista das enfermeiras, o paciente situa-se no núcleo da situação de ansiedade, portanto, quanto mais estreita a relação, maior a probabilidade de a enfermeira experimentar o aumento da ansiedade ${ }^{(15)}$.

Outro estudo revela que seria improvável se, em alguns momentos, a enfermeira não sentisse medo, insegurança, afinal, todos esses sentimentos são próprios da natureza humana ${ }^{(16)}$.

Assim, o serviço de enfermagem procura proteger-se da ansiedade fragmentando seu contato com os pacientes, alegando justificativas que vão desde a interferência na dinâmica do serviço até a falta de disponibilidade da equipe hospital.

Apesar de existirem numerosos estudos mostrando que a equipe se beneficia com a presença da família, alguns autores acreditam que os familiares podem se tornar causa do estresse psicológico da enfermeira, pelo fato de haver exigências e críticas dos pais a ela, sobretudo porque os incomoda a idéia de que a hospitalização implica na sua incapacidade de resolver o problema de seu filho ${ }^{(17-18)}$.

A dificuldade da família em entender e aceitar o estado do filho reflete considerações negativas em relação a sua presença, 0 horário da visita é trabalhoso para a enfermeira, pois é preciso dispensar atenção à família, além de realizar seu trabalho. A família começa a atrapalhar, e a tendência da enfermeira é preferir negar as visitas $^{(18)}$.

O uso de mecanismos de defesa inibe o desenvolvimento das capacidades que possibilitam a pessoa lidar com a realidade $e$ dominar a ansiedade e, deste modo, ela se sente desamparada diante das tarefas, situações e problemas novos ou estranhos. Considera, ainda, que optar por uma decisão implica eleger entre diferentes modelos de ações e comprometer-se com um deles ${ }^{(15)}$.

Este estudo mostrou-nos que a enfermeira considera as implicações de suas ações antes de decidir permitir ou não a presença dos pais na UTI Neonatal. No processo que envolve o pesar suas atitudes pessoais e a pressão social percebida por ela, sua intenção é desenvolvida em relação a este comportamento.

Compreendemos, por meio deste estudo, que a intenção da enfermeira foi fortemente determinada pelo fator social, ou seja, a motivação em garantir o cumprimento das normas da instituição relativas à presença dos pais. O fator pessoal, isto é, as suas atitudes

\section{REFERÊNCIAS BIBLIOGRÁFICAS}

1. Secretaria de Estado da Saúde (BR). Programa da "Mãe participante". Resolução 55-165 de 12 de outubro de 1988. Diário Oficial do Estado 1989; São Paulo, 14 mar: 13-4.

2. Angelo M. Abrir-se para a família: superando desafios. Família, Saúde Desenvolvimento 1999 jan/dez; 1(1/2):7-14. em relação à presença dos pais, interferiram na sua intenção, apenas naquelas situações especiais em que se via motivada a possibilitar o contato entre pais e recém-nascido.

Embora o valor explicativo do modelo da Teoria da Ação Racionalizada para o comportamento de permitir a presença dos pais na UTI neonatal seja limitado, os resultados deste estudo mostram, de fato, que a pressão institucional ou normas subjetivas exercem mais influência sobre as intenções da enfermeira do que suas atitudes pessoais. O modelo comportamental adotado proporcionou elementos que possibilitam explicação e até predição da ação da enfermeira.

As implicações deste conhecimento relacionam-se a um dos pressupostos da Teoria da Ação Racionalizada de que uma mudança na intenção produzirá uma mudança no comportamento. Isto significa que não bastaria expor a enfermeira a informações para que fossem alteradas as suas crenças.

Alterar uma ou mais crenças pode não ser suficiente para levar a uma mudança de atitude em geral. 0 efeito das variáveis externas sobre a enfermeira, por exercer um impacto expressivo sobre as suas intenções, é que parece merecer uma atenção especial.

$O$ valor destes resultados reside no fato de que predizer um comportamento a um nível coletivo é mais importante para fins de compreensão do que a nível individual, porque as intenções coletivas são mais estáveis no decorrer do tempo do que as individuais.

A utilização desta teoria como uma descrição do processamento de informações humanas é um recurso que nos auxilia a compreender a maneira como as pessoas, no caso específico a enfermeira, utiliza as informações disponíveis a ela de maneira racionalizada para chegar as suas decisões.

Isto não significa que seus comportamentos sejam sempre razoáveis ou apropriados. As informações são, às vezes, incompletas e até mesmo incorretas. No entanto, pode-se afirmar que 0 comportamento da enfermeira em relação aos pais na UTI Neonatal segue lógica e sistematicamente a informação que ela acredita ter disponível.

Para uma compreensão mais aprofundada, novos estudos devem ser realizados para demonstrar a necessidade de fatores adicionais que possam auxiliar a predizer ou compreender 0 comportamento da enfermeira.

3. Angelo M. Enfermagem em unidade de terapia intensiva pediátrica, além de atividades técnicas. Rev Esc Enfermagem USP 1980; 14(3):275-9.

4. Penticuff $\mathrm{JH}$. Ethics in pediatric nursing: advocacy and child's "determining self". Issues Compr Pediatr Nurs 1990 Jul-Sep; 13(3):221-9. 
5. Belli MA. De J. Assistência à mãe de recém-nascido internado na UTI Neonatal: Experiências, Expectativas e Sugestões Manifestadas por Mães e Enfermeiros. [dissertação]. São Paulo (SP): Escola de Enfermagem/USP; 1992.

6. Gennaro S. Facilitating parenting of the neonatal intensive care unit graduate. J Perinat Neonatal Nurs 1991; 4(4):55-61.

7. Klaus MH, Kennell JH. Pais/Bebês: a formação do apego. Porto Alegre (RS): Artes Médicas; 1992.

8. Barbosa VL. Conhecimentos e opiniões de enfermeiras sobre a participação da mãe na assistência ao recém-nascido prematuro. [dissertação]. São Paulo (SP): Escola Paulista de Medicina; 1990.

9. Bousso RS. Reflexões sobre o papel da enfermeira que atua em UTI pediátrica: aspectos emocionais em relação à família. Rev Esc Enfermagem USP 1987; 21(3):249-53.

10. Ajzen I, Fishbein M. Understanding attitudes and predicting social behavior. New Jersey: Englewood Cliffs; 1980.

11. Renfroe DH, O'Sullivan P, Mc Gee GW. The relationship of attitude, subjective norm and behavioral intent to the documentation behavior of nurses. Scholar Inquiry Nurs Practice 1990; 4:47-64.
12. Nash R, Edwards H, Nebauer M. Effect of attitudes, subjective norms and perceived control on nurses' intention to assess patients'pain. J Adv Nurs 1993; 18: 941-7.

13. Bardin L. Análise de Conteúdo. Lisboa (Portugal):Edições 70; 1977.

14. Wright LM, Watson WL, Bell JM. Beliefs- The heart of healing in families and illness. New York: Basic Books; 1996.

15. Menzies IEP. El funcionamento de los sistemas sociales como defensa contra la ansiedad. In: Menzies IEP, Jaques E. Los sistemas sociales como defensa contra la ansiedad. 3.ed. Buenos Aires: Hormé; 1974.

16. Ferreira PJO. O cuidar humano/profissional da pessoa que sente dor: virtudes de uma prática que visa o bem. [dissertação]. São Paulo (SP): Escola de Enfermagem/USP; 1997.

17. Neira HEdel P. Internação conjunta: critérios para decisão sobre que mães poderão acompanhar seus filhos durante a hospitalização. Rev Esc Enfermagem USP 1984; 18(1):13-21.

18. Takahashi EIU. As fontes de estresse emocional que afetam a enfermeira na assistência à criança grave. Rev Esc Enfermagem USP 1985; 19(1):5-20. 